\title{
Evaluation of Microbial Fuel Cells for Electricity Generation from Oil-Contaminated Wastewater
}

Kazuhiro Hamamoto ${ }^{1 *}$,Morio Miyahara ${ }^{2}$, Atsushi Kouzuma ${ }^{2}$, Akiteru Matsumoto ${ }^{1}$, Minoru Yoda ${ }^{1}$, Takashi Ishiguro ${ }^{1}$, Kazuya Watanabe ${ }^{2}$

${ }^{1}$ Miyoshi Oil and Fat Co., Ltd., 4-66-1,Horikiri, Katsushika-ku, Tokyo 124-8510, Japan

${ }^{2}$ School of Life Sciences, Tokyo University of Pharmacy and Life Sciences, 1432-1

Horinouchi, Hachioji, Tokyo 192-0392, Japan

${ }^{*}$ Corresponding author

Name: Kazuhiro Hamamoto

Affiliation; Foods Technology Division, Miyoshi Oil and Fat Co., Ltd

Phone numbers: $+81-3-3603-1115$

Fax numbers: +81-3-3603-1183

e-mail address: hamamotok@so.miyoshi-yushi.co.jp

Postal address: 4-66-1, Horikiri, Katsushika-ku, Tokyo 124-8510, Japan

Keywords food industry, vegetable oil, air cathode, anode coating, phylogenetic analyses 


\begin{abstract}
Large quantities of oils and fats are discharged into wastewater from food industries. We evaluated the possibility of using microbial fuel cells (MFCs) forthe generation of electricity from food-industry wastewater containing vegetable oils. Single-chamber MFCs were supplied with artificial wastewater containing soybean oil, and oil removal and electric output were examined under several different conditions. We found that MFC performancecould beimproved by supplementingwastewater with an emulsifier, inoculating MFCs with oil-contaminated soil, and coating the graphite-felt anodes with carbon nanotubes, resulting in a power output of more than 2 $\mathrm{W} \mathrm{m}^{-2}$ (based onthe projected area of the anode). Sequencing of polymerase chain reaction (PCR)-amplified 16S rRNA gene fragments detected abundant amount ofBurkholderiales bacteria (known to include oil degraders) in the oil-contaminated soil and anode biofilm, whereas those affiliated with the genus Geobacter were only detected in the anode biofilm. These results suggest thatMFCs can be used for energy recoveryfrom food industry wastewater containing vegetable oils.
\end{abstract}




\section{Introduction}

Large amounts of oils and fats are used in food industries. These include a range of vegetable oils and related organic compounds such as fats (triacylglycerol), fatty acids, glycerin, hydrocarbons, and waxes, and substantial amounts of these compounds are discharged as wastes. It has been reported that the amount of cooking-oil waste in Japan reaches up to 500,000 tons per year (1). These compounds are potentially valuable as fuels because they contain considerable amounts of energy, e.g., $38 \mathrm{~kJ}$ per gram of lipids, more than those contained in carbohydrates and proteins. In many cases, however, it is difficult to use waste oils as fuels because they are mixed with large amounts of water or are present in wastewater.

Microbial fuel cells (MFCs), which exploit living microbes as electrode catalysts, have recently attracted considerable attention as green energy devices for generating electricity from various organic and inorganic materials $(2,3)$. Workers are interested in using MFCs for recovering energy from biomass waste and wastewater (4). In MFCs, microbes degrade pollutants using anodes in place of oxygen as respiratory electron acceptors, thereby enabling aeration-free wastewater treatment. In addition, microbes retain less energy during the generation of electricity than that during aerobic processes, meaning that the amount of sludge discharged during wastewater treatment can be markedly reduced. MFCs are therefore expected to have applications in energy- and cost-efficient wastewater treatment processes(5-8).

MFCs have been examined for electricity generation from various compounds, including organic acids (9), carbohydrates $(10,11)$, and proteins (12), and extensive efforts havebeen made to develop technologies that boost power output from MFCs (13-15). Electricity generation from short-chain fatty acids has also been examined (16). 
To our knowledge, however, there has been no report that hassuccessfully used vegetable oils as substrates for electricity generation in MFCs. The aims of the present study were to evaluate MFCs for electricity generation from vegetable oils (e.g., soybean oil) andgain insight into how microbes convert vegetable oils into electricity.

\section{Materials and Methods}

MFC setups

Single-chamber MFCs ( $18 \mathrm{~mL}$ capacity) equipped with anodes $\left(2.6 \mathrm{~cm}^{2}\right.$ projected areain each cell) and air cathodes $\left(7 \mathrm{~cm}^{2}\right.$ in each cell) were used. An anode was made of graphite felt (GF, cat no. GF-80-3F, Sohgoh Carbon, Yokohama, Japan), and in some experiments, graphite felt coated with carbon nanotubes (CNTs) (17) was used as an anode material. An air cathode was made of carbon cloth (cat no. TCC-3250, Toho Tenax, Tokyo, Japan) and was coated with fourpolytetrafluoroethylene layers on one side and platinum catalysts $\left(0.1 \mathrm{mg}\right.$ platinum $\mathrm{cm}^{-2}$; TEC10E20TPM, Tanaka Kikinzoku Kogyo, Tokyo, Japan) on the other side (13). A filter paper (cat. no.1004-240, GE Healthcare, Tokyo, Japan) was sandwiched between the anode and cathode to preventthem from making contact. The anode and cathode were electrically connected through an external resistor, $R_{\text {ext }}$ (termed closed-circuit MFC, CC-MFC), and voltages across the resistor were monitored using a data logger (HA-1510, Graphtec, Yokohama, Japan).

Artificial oil-contaminated wastewater 
An artificial oil-contaminated wastewater contained soybean oil $\left(20 \mathrm{~g} \mathrm{~L} \mathrm{~L}^{-1}\right)$, $\left(\mathrm{NH}_{4}\right)_{2} \mathrm{SO}_{4}\left(2.22 \mathrm{~g} \mathrm{~L}^{-1}\right), \mathrm{KH}_{2} \mathrm{PO}_{4}\left(6.30 \mathrm{~g} \mathrm{~L}^{-1}\right), \mathrm{Na}_{2} \mathrm{HPO}_{4}\left(7.10 \mathrm{~g} \mathrm{~L}^{-1}\right), \mathrm{MgSO}_{4} \cdot 7 \mathrm{H}_{2} \mathrm{O}$

$\left(0.11 \mathrm{~g} \mathrm{~L}^{-1}\right), \mathrm{FeSO}_{4} \cdot 7 \mathrm{H}_{2} \mathrm{O}\left(0.01 \mathrm{~g} \mathrm{~L}^{-1}\right), \mathrm{CaCl}_{2} \cdot 2 \mathrm{H}_{2} \mathrm{O}\left(0.01 \mathrm{~g} \mathrm{~L}^{-1}\right), \mathrm{MnCl}_{2} \cdot 4 \mathrm{H}_{2} \mathrm{O}(0.01 \mathrm{~g}$ $\left.\mathrm{L}^{-1}\right)$, and Dificoyeast extract $\left(0.11 \mathrm{~g} \mathrm{~L}^{-1}\right)$ ( $\mathrm{pH}$ 7.0). The chemical oxygen-demand $\left(\mathrm{COD}_{\mathrm{cr}}\right)$ of the artificial wastewater was approximately $40 \mathrm{~g} \mathrm{~L}^{-1}$. In some experiments, the artificial wastewater was supplemented with Tween 20 (as an emulsifier) at a concentration of $1 \mathrm{gL}^{-1}$. Before use, the artificial wastewater was treated with a homogenizer (HV-0A-1-1.5s, Izumi Food Machinery, Hyogo, Japan) and sterilized by autoclaving.

Operation of MFCs

The microbial inocula used in the present study werenon-contaminated garden soil (NC-soil); oil-contaminated soil sampled from an edible oil factory in Tokyo (OC-soil); and activated sludge sampled from the wastewater treatment facility of an edible oil factory (WO-sludge). An MFC reactor was filled with $16 \mathrm{ml}$ of the artificial oil-contaminated wastewater, and after being bubbled with pure nitrogen gas, it was inoculated with one of these inocula( 0.9 gram, wet weight $)$ suspended in sterilized water. Unless otherwise stated, $R_{\text {ext }}$ was set at $10,000 \Omega$. The MFC reactors were placed in an incubator (maintained at $30^{\circ} \mathrm{C}$ ), and the cell voltage was automatically monitored using the logger. For comparing anode microbial communities, some MFC reactors whose anode and cathode were not connected (open circuit, OC-MFC) were also operated.

\section{Measurements of MFC parameters}


$\mathrm{COD}_{\mathrm{cr}}$ was measured using a COD meter (DR 2800,Hach, Loveland, CO, USA) and a COD 0-1,500 ppm range kit (Hach). MFC performance was evaluated according to the method described elsewhere (2). Current $(I, \mathrm{~A})$ was calculated using the equation $I=$ $E / R$, where $E(\mathrm{~V})$ is cell voltage, and $R(\mathrm{ohm})$ is resistance, whereas current density $(J$, $\left.\mathrm{A} \mathrm{cm}^{-2}\right)$ was calculated based on the projected area of the anode $\left(2.6 \mathrm{~cm}^{2}\right)$. Coulombic efficiency $(\varepsilon)$ was calculated by dividing the total charge (coulombs) transferred to the anode by the theoretical maximum charge (the total coulombs produced by complete substrate oxidation to carbon dioxide). Polarization and power-density curves were drawn as described previously (2) using a potentiostat (HSV-100, Hokuto Denko, Tokyo, Japan).An internal resistance $\left(R_{\text {int }}\right)$ and maximum power density $\left(P_{\max }\right)$ were obtained from these curves.

Microbial community analyses

DNA was extracted from the OC-soil $(0.5 \mathrm{~g})$, and GF pieces in CC-MFC and OC-MFC $(5 \mathrm{~mm} \times 5 \mathrm{~mm}$ in total size) using aFAST DNA Spin Kit for Soil (Q-Bio, Carlsbad, CA, USA) according tothe manufacturer's instructions. PCR amplification of $16 \mathrm{~S}$ rRNA gene fragments was performed using U27f (5'-AGAGTTTGATCMTGGCTCAG-3', nucleotide position 27 to 46 in the Escherichia coli sequence) as a forward primer and U1492r (5'-GGYTACCTTGTTACGACTT-3', nucleotide position 1492 to 1510) as a reverse primer (18). A PCR buffer $(50 \mu \mathrm{L})$ contained $1.25 \mathrm{U}$ of DNA polymerase (KOD dash, Toyobo, Tokyo), $0.2 \mathrm{mMdNTPs}, 0.2 \mu \mathrm{M}$ of each primer and an appropriate amount of template DNA. The amplification conditions were as follows: an initial step at $94^{\circ} \mathrm{C}$ for $3 \mathrm{~min}$; 30 cycles consisting of $94^{\circ} \mathrm{C}$ for $30 \mathrm{sec}, 50^{\circ} \mathrm{C}$ for $30 \mathrm{sec}$, and $74^{\circ} \mathrm{C}$ for $30 \mathrm{sec}$; and a final elongation step at $74^{\circ} \mathrm{C}$ for $3 \mathrm{~min}$. Amplified fragments were 
purified with a QIAquick PCR Purification Kit (Qiagen, Tokyo, Japan), ligated into the pGEM-T vector (Promega, Tokyo, Japan), and cloned into competent cells (E.coli JM109, Takara, Shiga, Japan) as described elsewhere (18).Clones containing appropriate sizes of the insertion were selected by electrophoresis analysis, and their nucleotide sequences were determined as described previously (19). Nucleotide sequences obtained from clone libraries (OC-soil, CC-MFC, and OC-MFC) were aligned to each other using the MEGA program ver. 5.1 (20), and assigned to phylotypes (classified as a unique clone or group of clones with sequence similarity of $>0.98$ ). Database searches were conducted using the BLAST program (21) and the GenBank database.

The nucleotide sequences determined in the present study were deposited in the DDBJ, EMBL, and NCBI nucleotide sequence databases under accession numbers AB91123 to AB91139.

\section{Results}

Effects of emulsifier

As the initial step, we examined electricity generation in MFCs that were filled with the artificial oil-contaminated wastewater and inoculated with NC-soil. This soil sample was used, because previous studies have successfully used similar soils as inocula for MFCs treating organic substrates $(8,15$, and 19$)$.However, the current density $(J)$ did not increase during the 25-day experiment (Fig. 1). We believed that this was due to the low solubility of the oils in water and examined whether supplementation of the artificial wastewater with the emulsifiercould increaseelectrical output fromthe MFCs 
(Fig. 1).We found that, in MFC supplemented with the emulsifier, $J$ started to increase from day 10 and reached $6 \mu \mathrm{A} \mathrm{cm}^{-2}$ on day 20.This demonstrated the utility of an emulsifier for generating electricity from vegetable oils in an MFC.

Effects of inocula

Wealso examined the effects ofmicrobial inocula on electricity generation from vegetable oils (the emulsifier was not added). We operated the MFCs that were filled with the artificial oil-contaminated wastewater and inoculated them with either NC-soil, OC-soil,or WO-sludge. We believed that microbial sources that areacclimatized to oily materials would be beneficial to an MFC for treating recalcitrant oil components. We operated these MFCs for approximately 20 daysand found that theMFC inoculated with OC-soil generated the highest $J$, followed by the MFC inoculated with WO-sludge (Fig. 2).

Effects of anode modification

Previous studies have developed methods for modifying anode surfaces for enhancing the power output from MFCs $(17,22$, and 23). Among these,direct modification the of graphite anodes with CNTs is attractive, since a modified anode is stable for a long time even in the presence of anaerobic microbial communities (17). Furthermore, we considered that the hydrophobic surfaces of the CNTs could preferentially trap large amounts of oils from wastewater and promote the microbial attack. In the present study, we examined the utility of CNT-modified graphite felt (CNT-GF) as an anode material for MFCs treating vegetable oil, and we compared its power output with that of an MFC 
equipped with the non-modified GF anode. In this trial, according to the results of the aforementioned experiments, the artificial oil-contaminated wastewater was supplemented with the emulsifier, and OC-soil was used as the inoculum. We found thatthe electrical output from the MFC equipped with the CNT-GF anode was much greater than that from the MFC with the nonmodified GF anode (Fig. 3); this was clearly shown after $R_{\text {ext }}$ was changed from 10,000 to $1,000 \Omega$, and then further decreased to $100 \Omega$.At $R_{\text {ext }}$ of $100 \Omega$, Jof CNT-GF MFC reached $500 \mu \mathrm{A} \mathrm{cm}{ }^{-2}$ (Fig. 3).

Polarization analyses were conducted for theoil-fueled MFC with CNT-GF (Fig. 4), and the performance data are summarized in Table 1. It is shown that $P_{\max }$ of this MFC reached $2.24 \mathrm{~W} \mathrm{~m}^{-2}$. At a $R_{\text {ext }}$ of $100 \Omega, \varepsilon$ was estimated to be approximately $20 \%$ (Table 1).It is considered thatthe oil was also decomposed into $\mathrm{CO}_{2}$ by aerobic respiration and converted into biomass, resulting in the relative low $\varepsilon$ value compared to the $\mathrm{COD}_{\mathrm{cr}}$-removal rate.

Microbes in oil-fueled MFC

We were interested in identifying themicrobes that were involved in the conversion of vegetable oil into electricity. For this purpose, we carried out molecular phylogenetic analyses (based on PCR-amplified 16S rRNA gene fragments) of microbes occurring in the anode biofilms in the MFC (CC-MFC) whose performances are presented in Fig. 4 and Table 1. Furthermore, in order to identify the microbes that specifically occurred under the electricity-generating conditions, microbes in the OC-soil (the inoculum) and those adhering to the graphite felt in the OC-MFC reactor were comparatively analyzed. We obtained 80 to 100 sequences from each of the three libraries (namely, OC-soil, OC-MFC, and CC-MFC) and classified them into phylotypes that corresponded to 
species-level phylogenetic groups (Table 2).

Phylogenetic analyses uncovered several notable features of the three microbial communities, whichhelpus understand how the microbes worked in the oil-fueled MFC (Table 2). First, phylotypeODM09was abundantly detected in all three libraries. This phylotypeis closely related to Ideonelladechloratans, which is known to include chlorate-reducing bacteria (24).Next, phylotypes affiliated with the phylumFirmicutes were detected in abundance from the OC-MFC (Table 2); organisms closely related to these phylotypes include Propionisporavibrioides, Sporobactertermitidis, Eubacteriumcontortum, and Clostridium celerecrescens. Finally, two phylotypes (ODM07 and ODM16) specifically appeared in the CC-MFC library (Table 2). OCM07 is closely related to Laribacterhongkongensis(25), whereasODM16 is closely related to Geobactermetallireducens (26).

\section{Discussion}

The present study showed that anMFC generated electricity, using withsoybean oil as the fuel,at relatively high power densities, e.g., over $2 \mathrm{~W} \mathrm{~m}^{-2}$. These power densitiesare equivalent to those reported for MFCs using organic fuels susceptible to microbial metabolism $(27,28)$. The results thussupport the notion that MFCsare potentially applicable tothe recovery of electrical energy from oil-contaminated wastewater discharged from food industries.It isalso important to note that this high power density was achieved after examination of factors that had been considered important for oil/electricity conversion, e.g., surfactants, microbial inocula, and CNT-coated anodes. Because the factors examined in the present study were limited, we expect that future studies will be able to further enhance the electrical output from MFCs fueled with 
vegetable oils.

Molecular phylogenetic analyses of microbial communities also suggest the importance of microbial inocula for oil/electricity conversion. Phylotype ODM09was present in OC-soil that was used as the inocula for the MFC reactors (OC-MFC and CC-MFC) treating the vegetable oil,and it remained in these reactors as the most abundant phylotype. This phylotypeis affiliated with the order Burkholderiales andis related to the genera Aquabacterium, Rubrivivax, and Sphaerotilus. Bacterial strains affiliated with these genera are known to metabolize oils, fats, and hydrocarbons (29-31). Accordingly, it is likely that bacteria represented by this phylotype were responsible forthe oil degradation in these ecosystems. The observation that abundant bacteria remained in the inoculum as major populations after the vegetable oil operation suggests the importance of microbial inocula for oil/electricity conversion.

The phylum Firmicutes was isolated from anaerobic environments and is known to ferment a variety of compounds (32-35). It is likely that organisms represented by these phylotypes may have occurred by fermenting intermediate metabolites produced from oil in the absence of electron acceptors in OC-MFC.On the other hand, two phylotypes (ODM07 and ODM16) specifically appeared in the CC-MFC library. Among these, ODM07 is closely related toLaribacterhongkongensism, which has been isolated from clinical samples (25). Although closely related sequences have not been detected previously from microbial communities in MFCs, according to previous studies $(9,19)$ that also compared microbial communities in open- and closed-circuit reactors, the specific detection suggests the possibility that organisms represented by this phylotype were involved in electricity generation in the oil-fueled MFC. ODM16 is closely related toGeobactermetallireducens, a well-known iron-reducing bacterium capable of anode respiration in MFCs (26). It is therefore likely 
that ODM16 represents organisms that were directly involved in electricity generation in the oil-fueled MFC.Wethink that the establishment of metabolic interactions between oil-degrading microbes and electricity-generating microbes are the key to developing MFCs that efficiently generate electricity from vegetable oils.

In future studies, we will utilize information gained in the present study to examine MFCs for the treatment of actual oil-contaminated wastewater and to isolate and characterize micro-organisms that play important roles in oil-fueled MFCs. We will also examine scaled-up MFC reactors to gain quantitative data on the material balance and the increase in biomass in association with oil treatment by MFCs.

\section{Acknowledgments}

We thank Kazuhito Hashimoto for valuable adviceand Ayako Matsuzawa for technical assistance. This work was supported in part by the Exploratory Research for Advanced Technology (ERATO) program of the Japanese Science and Technology Agency (JST).

\section{References}

1. Ministry of Agriculture, Forestry and Fisheries of Japan: Statistic data on the production of oils and fats in Japan. Ministry of Agriculture, Forestry and Fisheries of Japan (2011)

2. Logan, B. E., Hamelers, B., Rozendal, R., Schröder, U., Keller, J., Freguia, S., Aelterman, P., Verstraete, W. andRabaey, K.: Microbial fuel cells: methodology and technology, Environ. Sci. Technol., 40, 5181-5192 (2006).

3. Watanabe, K.: Recent developments in microbial fuel cell technologies for 
sustainable bioenergy, J.Biosci.Bioeng.,106, 528-536 (2008).

4. Lefebvre, O., Uzabiaga, A., Chang, I., Kim, B. H. and Ng, H. Y.: Microbial fuel cells for energy self-sufficient domestic wastewater treatment; a review and discussion from energetic consideration, Appl.Microbiol.Biotechnol.,89, 259-270 (2011).

5. He, Z., Minteer, S. D. andAngenent, L. T.: Electricity generation from artificial wastewater using an upflow microbial fuel cell, Environ. Sci. Technol., 39, 5262-5267 (2005).

6. Liu, H., Ramnarayanan, R. and Logan, B. E.: Production of electricity during wastewater treatment using a single chamber microbial fuel cell, Environ. Sci. Technol., 38, 2281-2285 (2004).

7. Rozendal, R. A., Hamelers, H. V. M.,Rabaey, K., Keller, J. andBuisman, C. J. N.: Towards practical implementation of bioelectrochemical wastewater treatment, Trends.Biotechnol.,26, 450-459 (2008).

8. Miyahara, M., Hashimoto, K. and Watanabe, K.: Use of cassette-electrode microbial fuel cell for wastewater treatment, J.Biosci.Bioeng.,115, 176-181 (2013).

9. De Cárcer, D. A., Ha, P. T., Jang, J. K. and Chang, I. S.: Microbial community differences between propionate-fed microbial fuel cell systems under open and closed circuit conditions, Appl.Microbiol.Biotechnol.,89, 605-612 (2011).

10. Niessen, J., Schröder, U. andScholz, F.: Exploiting complex carbohydrates for microbial electricity generation - a bacterial fuel cell operating on starch,Electrochem.Commun.,6, 955-958 (2004).

11. Rabaey, K., Lissens, G., Siciliano, S. D. andVerstraete, W.: A microbial fuel cell capable of converting glucose to electricity at high rate and efficiency,Biotechnol.Let.,25, 1531-1535 (2003). 
12. Heilmann, J. and Logan, B.E.: Production of electricity from proteins using a microbial fuel cell, Wat. Environ. Res., 78, 531-537 (2006).

13. Cheng, S., Liu, H. and Logan, B. E.: Increased performance of single-chamber microbial fuel cells using an improved cathode structure,Electrochem.Commun.,8, 489-494 (2006).

14. Oh, S. E. and Logan, B. E.: Proton exchange membrane and electrode surface areas as factors that affect power generation in microbial fuel cells, Appl.Microbiol.Biotechnol.,70, 162-169 (2006).

15. Shimoyama, T., Komukai, S., Yamazawa, A., Ueno, Y., Logan, B. E., Watanabe,K.: Electricity generation from model organic wastewater in a cassette-electrode microbial fuel cell, Appl.Microbiol.Biotechnol. 80, 325-330 (2008).

16. Freguia, S., Teh, E. H., Boon, N., Leung, K. M., Keller, J. andRabaey, K.: Microbial fuel cells operating on mixed fatty acids,Biores. Technol.,101, $1233-1238$ (2010).

17. Zhao, Y., Watanabe, K. and Hashimoto, K.: Hierarchical micro/nano structures of carbon composites as anodes for microbial fuel cells, Phys. Chem. Chem. Phys., 13, 15016-15021 (2011).

18. Watanabe, K., Kodama, Y. andKaku, N.: Diversity and abundance of bacteria in an underground oil-storage cavity, BMC Microbial., 2, 23 (2002).

19. Ishii, S., Hotta, Y. and Watanabe, K.: Methanogenesis versus electrogenesis: morphological and phylogenetic comparisons of microbial communities,Biosci.Biotechnol.Biochem.,72, 286-294 (2008).

20. Tamura, K., Peterson, D., Peterson, N., Stecher, G., Nei, M. and Kumar, S.: MEGA5: molecular evolutionary genetics analysis using maximum likelihood, 
evolutionary distance, and maximum parsimony methods, Mol. Biol.Evol., 28, 2731-2739 (2011).

21. Karlin, S. andAltschul, S. F.: Methods for assessing the statistical significance of molecular sequence features by using general scoring schemes, Proc. Natl. Acad. Sci. USA., 87, 2264-2268 (1990).

22. Schröder, U., Nießen, J. andScholz, F.: A generation of microbial fuel cells with current outputs boosted by more than one order of magnitude,Angew. Chem. Int. Ed., 42, 2880-2883 (2003).

23. Zhao, Y., Watanabe, K., Nakamura, R., Mori, S., Liu, H., Ishii, K. and Hashimoto, K.: Three-dimensional conductive nanowire networks for maximizing anode performance in microbial fuel cells, Chem. Eur. J., 16, 4982-4985 (2010).

24. Malmqvist, A., Welander, T., Moore, E., Ternstrom, A., Molin, G. andStenstrom, I.:Ideonelladechloratans, gen. nov., sp. nov., a new bacterium capable of growing anaerobically with chlorate as an electron acceptor, Syst. Appl.Microbiol., 17, 58-64 (1994).

25. Yuen, K. Y., Woo, P. C., Teng, J. L., Leung, K. W., Wong, M. K. and Lau, S. K.:Laribacterhongkongensis gen. nov., sp. nov., a novel gram-negative bacterium isolated from a cirrhotic patient with bacteremia and empyema, J.Clin.Microbiol.,39, 4227-4232 (2001).

26. Lovley, D. R.: Bug juice: harvesting electricity with microorganisms, Nat. Rev.Microbiol., 4, 497-508 (2006).

27. Logan, B. E. and Regan, J. M.: Electricity-producing bacterial communities in microbial fuel cells, Trends.Microbiol.,14, 512-518 (2006).

28. Feng, Y., Yang, Q., Wang, X., Liu, Y., Lee, H. and Ren, N.: Treatment of biodiesel production wastes with simultaneous electricity generation using a single-chamber 
microbial fuel cell,Biores. Technol., 102, 411-415 (2011).

29. Lo, K. W., Chua, H., Lawford, H., Lo, W. H. and Yu, P. H.: Effects of fatty acids on growth and poly-3-hydroxybutyrate production in bacteria, Appl.Biochem.Biotechnol.,124, 575-580 (2005).

30. Mikkonen, A., Lappi, K., Wallenius, K., Lindström, K. andSuominen, L.: Ecological inference on bacterial succession using curve-based community fingerprint data analysis, demonstrated with rhizoremediation experiment, FEMS Microbiol. Ecol., 78, 604-616 (2011).

31. Ramana, C. V., Sasikala, C., Arunasri, K., Anil, K. P., Srinivas, T. N., Shivaji, S., Gupta, P., Süling, J. andImhoff, J. F.:Rubrivivaxbenzoatilyticus sp. nov., an aromatic, hydrocarbon-degrading purple betaproteobacterium, Int. J. Syst.Evol.Microbiol.,56, 2157-2164 (2006).

32. Biebl, H., Schwab-Hanisch, H., Sproer, C. andLunsdorf, H.:Propionisporavibrioides, nov. gen., nov. sp., a new gram-negative, spore-forming anaerobe that ferments sugar alcohols, Arch.Microbiol., 174, 239-247 (2000).

33. Chamkha, M., Garcia, J. L. andLabat, M.: Metabolism of cinnamic acids by some Clostridiales and emendation of the descriptions of Clostridium aerotolerans, Clostridium celerecrescens and Clostridium xylanolyticum, Int. J. Syst.Evol.Microbiol.,51, 2105-2111 (2001).

34. Grech-Mora, I., Fardeau, M. L., Patel, B. K. C., Ollivier, B., Rimbault, A., Prensier, G., Garcia, J. L. andGarnier-Sillam, E.: Isolation and characterization of Sporobactertermitidis gen. nov., sp. nov., from the digestive tract of the wood-feeding termite Nasutitermeslujae, Int. J. Syst.Bacteriol., 46, 512-518(1996).

35. Holdeman, L. V., Cato, E. P. and Moore, W. E. C.:Eubacteriumcontortum 
(Prevot) comb. nov.: Emendation of description and designation of the type strain,Int. J. Syst.Bacteriol., 21, 304-306 (1971). 


\section{Figure legend}

Fig. 1 Effects of the emulsifier on electricity generation in the oil-fueled MFCs.

Fig. 2 Effects of microbial inocula on electricity generation in the oil-fueled MFCs.

Fig. 3 Effects of the CNT-GF anode on electricity generation in the oil-fueled MFCs.

The arrow indicates time points at which external resisters were changed $(10,000 \Omega$ to $1,000 \Omega$ on day 18 and $1,000 \Omega$ to $100 \Omega$ on day 36 ).

Fig. 4 Polarization and power curves showing electrochemical performances of the oil-fueled MFCs equipped with the CNT-GF anode. 
Table 1 Summary of performance data for the oil-fueled MFC

\begin{tabular}{ll}
\hline Parameter & Value \\
\hline Max power density, $P_{\max }$ & \\
per reactor volume $\left(\mathrm{W} \mathrm{m}^{-3}\right)$ & 31.6 \\
per projected area of anode $\left(\mathrm{W} \mathrm{m}^{-2}\right)$ & 2.24 \\
Open circuit voltage $(\mathrm{V})$ & 0.46 \\
Shot circuit current density $\left(\mathrm{Am}^{-2}\right)$ & 6.58 \\
Internal resistance, $R_{\text {int }}(\Omega)$ & 132 \\
Coulombic efficiency, $\varepsilon(\%)$ & 20.1 \\
$\mathrm{COD}_{\text {cr-removal rate }}(\%)$ & 77.9 \\
\hline
\end{tabular}


Table 2 Majorphylotypes detected in the OC-soil, OC-MFC and CC-MFC libraries*

\begin{tabular}{|c|c|c|c|c|c|}
\hline \multirow{2}{*}{ Phylogenetic group } & \multirow{2}{*}{ Phylotype } & \multicolumn{3}{|c|}{ Number of clone } & \multirow{2}{*}{ Closely related organism, accession number ( $\%$ match) } \\
\hline & & OC-soil & OC-MFC & CC-MFC & \\
\hline \multirow[t]{7}{*}{ Firmicutes } & ODM01 & 11 & & 3 & Selenomonaslacticifex,NR_104863 (94) \\
\hline & ODM02 & 1 & 5 & 1 & Propionisporavibrioides, $\bar{N}$ R_025418 (98) \\
\hline & ODM03 & & 9 & 1 & Sporobactertermitidis, NR_044972 (95) \\
\hline & ODM04 & 2 & 1 & & Clostridium frigidicarnis, NR_024919 (96) \\
\hline & ODM05 & & 7 & & Eubacteriumcontortum, NR_104803 (94) \\
\hline & ODM06 & & 5 & & Clostridium celerecrescens, NR_026100 (99) \\
\hline & Others & 4 & 9 & 1 & \\
\hline Alphaproteobacteria & & 2 & 3 & 1 & \\
\hline \multirow[t]{8}{*}{ Betaproteobacteria } & ODM07 & 2 & & 14 & Laribacterhongkongensis, NR_025167 (96) \\
\hline & ODM08 & 23 & & 4 & Acidovoraxebreus, NR_074591 (98) \\
\hline & ODM09 & 22 & 22 & 23 & Ideonelladechloratans, NR_026108 (99) \\
\hline & ODM10 & 2 & & 1 & Alcaligenesaquatilis, NR_104977 (99) \\
\hline & ODM11 & 1 & 1 & & Bordetellapetrii, NR_074̄291 (99) \\
\hline & ODM12 & & 6 & 3 & Azospirarestricta, $\mathrm{NR}$ _044023 (97) \\
\hline & ODM13 & & 12 & & Azospiraoryzae, NR_024852 (98) \\
\hline & Others & 5 & & 6 & \\
\hline \multirow{2}{*}{ Gammaproteobacteria } & ODM14 & 8 & & & Acinetobacterjohnsonii, NR_044975 (99) \\
\hline & Others & 2 & & 5 & \\
\hline \multirow[t]{3}{*}{ Deltaproteobacteria } & ODM15 & & 6 & 1 & Desulfovibriodesulfuricans, NR_104990 (99) \\
\hline & ODM16 & & & 13 & Geobactermetallireducens, NR_075011 (97) \\
\hline & Others & & 1 & 7 & \\
\hline Acidobacteriales & ODM17 & 6 & & & CandidatusChloracidobacteriumthermophilum, NR_074296 (83) \\
\hline Actinobacteria & & 1 & & & \\
\hline Bacteroidetes & & & & 2 & \\
\hline Chloroflexi & & 2 & & & \\
\hline Planktomycetes & & 1 & & & \\
\hline Unclassified bacteria & & 5 & & 3 & \\
\hline Total & & 100 & 87 & 89 & \\
\hline
\end{tabular}

*Phylotypes that include more than 2 cloned sequences are analyzed. 
Fig. 1 Hamamoto et al.

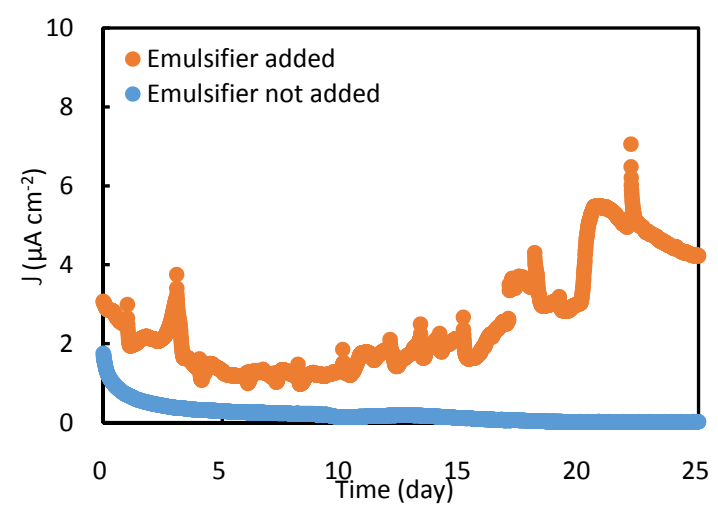


Fig. 2 Hamamoto et al.

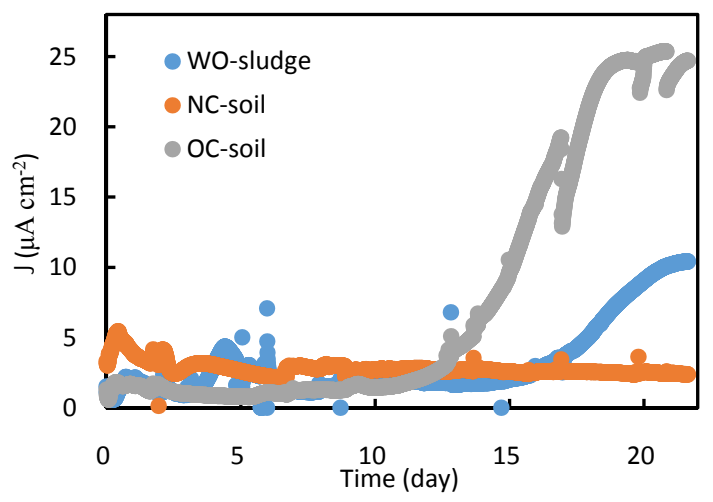


Fig. 3 Hamamoto et al.

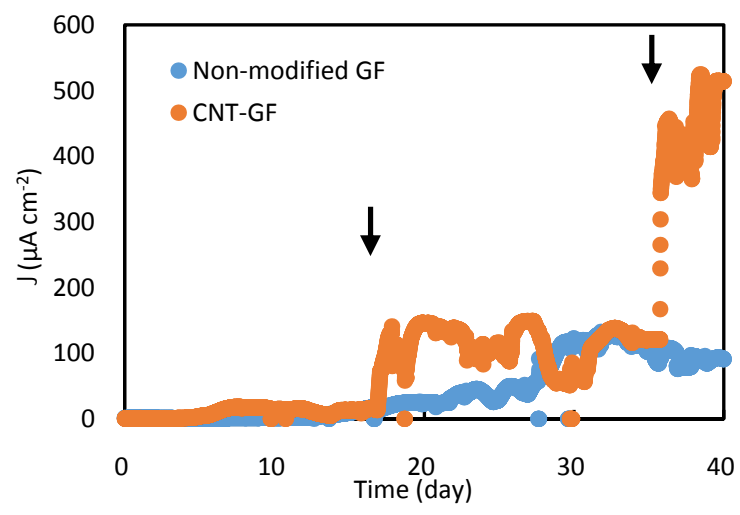


Fig. 4 Hamamoto et al.

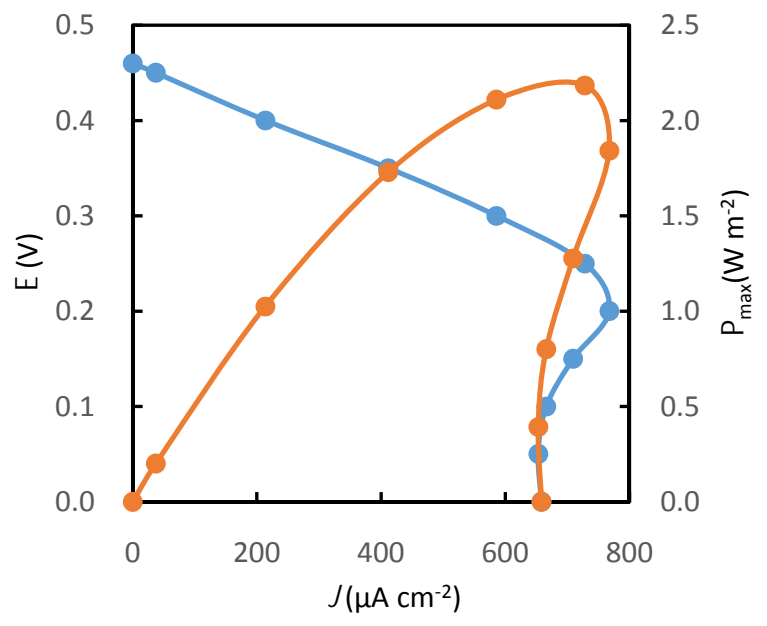

